\title{
Ekstraksi Benda Asing Lampu Led di Bronkus dengan Bronkoskop Kaku
}

\author{
Fachzi Fitri, Tuti Nelvia
}

\begin{abstract}
Abstrak
Aspirasi benda asing adalah masalah yang relatif sering ditemukan pada anak dan merupakan masalah serius yang bisa berakibat fatal. Benda asing di traktus respiratorius harus segera dikeluarkan dalam kondisi dan peralatan optimal dan dengan trauma yang seminimal mungkin untuk mencegah komplikasi. Instrumen yang digunakan untuk tindakan ekstraksi benda asing dapat mempengaruhi morbiditas akibat komplikasi ekstraksi benda asing di traktus respiratorius. Dilaporkan satu kasus aspirasi lampu LED (Light Emitting Diode) di bronkus utama kanan pada anak perempuan berumur 5 tahun, yang dua kali gagal dikeluarkan dengan bronkoskop fleksibel dan berhasil dikeluarkan dengan menggunakan bronkoskop kaku tanpa komplikasi.
\end{abstract}

Kata kunci: aspirasi benda asing, lampu LED, bronkoskop kaku

\begin{abstract}
Foreign body aspiration is a relative commonly problem in children and still a serious and sometimes fatal condition. Foreign body in respiratory tract must be removed in optimal conditions and equipment with minimal trauma to prevent complications. Instruments which being used for foreign body extraction can affect morbidity due to complications of extraction of foreign body in respiratory tract. There was reported one case of aspiration of LED (Light Emitting Diode) lamp in the right main bronchus of 5 year old girl, who failed two times by flexible bronchoscope and successfully extracted by a rigid bronchoscope, without complication.
\end{abstract}

Keywords: foreign body aspiration, LED lamp, rigid bronchoscope

Affiliasi penulis : Bagian THT-KL Fakultas Kedokteran Universitas Andalas,

Korespondensi :Tuti Nelvia, email : tutinelvia@gmail.com, Telp: 08126724910

\section{PENDAHULUAN}

Aspirasi bendaasingadalah masalahyang penting sebagai penyebab kesakitan dan kematian pada anak dibawah umur 6 tahun. Pada negara berkembang diperkirakan 300-600 anak pertahun meninggal dibawah usia 15 tahun karena aspirasi benda asing.

LED (light-emitting diode) adalah suatu semikonduktor yang memancarkan cahaya monokromatik yang tidak koheren ketika diberi tegangan maju. Chip LED mempunyai kutub positif dan negatif, yang terbuat dari kaca dan berbagai logam, diantaranya zinc, germanium, aluminiumdan galium. ${ }^{2}$
Predileksi tersering tersangkutnya benda asing di saluran nafas adalah di bronkus utama kanan karena lebih luas dan lebih lurus dibandingkan dengan bronkus utama kiri. Aspirasi benda asing sering terjadi pada usia anak disebabkan karena anak lebih aktif, cenderung memasukkan sesuatu ke mulut serta kurangnya pengawasan dari orang tua. ${ }^{3-5}$ Anamnesis yang baik, pemeriksaaan fisikdan pemeriksaan radiologi penting untuk menegakkan diagnosis aspirasi benda asing pada saluran nafas, tapi sering kali masih merupakan suatu masalah karena tidak khas. ${ }^{4}$

Benda asing yang teraspirasi dikelompokkan menjadi dua kategori yaitu organik dan inorganik. Benda asing organik yang sering ditemukan pada anak adalah kacang. Aspirasi benda asing inorganik yang sering ditemukan pada anak adalah coin, peniti, 
bagian kecil dari mainan dan peralatan sekolah. Jenis benda yang teraspirasi dipengaruhi budaya, wilayah dan gaya hidup., ${ }^{3,6-8}$

Pada tahun 1895, Killian memperkenalkan alat untuk tindakan bronkoskopi dan dua tahun setelah itu berhasil mengeluarkan benda asing sepotong tulang pada bronkus. Di Amerika Algernon Coolidge Jr adalah orang pertama pada rumah sakit Massachusetts pada tahun 1899, melakukan bronkoskopi melalui trakeostomi dan mengeluarkan anak kanul trakeostomi pada bronkus seorang wanita berumur 23 tahun. Pada awal 1900 Chevalier Jackson mempelopori pembuatan alat-alat untuk endoskopi saluran nafas yang lebih praktis dan aman sedangkan fiber seratoptik diperkenalkan tahun $1960 .^{8}$

Bronkoskop kaku merupakan pilihan untuk ekstraksi benda asing yang teraspirasi pada anak, karena ventilasi lebih terjamin karena mempunyai konektor yang dihubungkan dengan oksigen, lebih mudah untuk melakukan tindakan dan bisa untuk mengatasi perdarahan. ${ }^{7}$

Komplikasi yang mungkin terjadi pada aspirasi benda asing di trakeobronkial dapat akibat benda asing sendiri dan tindakan bronkoskopi. Komplikasi akibat benda asing yang paling sering berupa infeksi paru dan kelainan lain seperti edema, tracheitis, bronkitis atau timbulnya jaringan granulasi dan atelektasis. Komplikasi yang berhubungan dengan tindakan bronkoskopi intra operatif yang paling sering adalah aritmia jantung, bronkospasme, edema laring, juga trauma pada gigi, bibir, gusi dan laring. ${ }^{9,10}$

\section{LAPORAN KASUS}

Seorang pasien anak perempuan berusia 5 tahun, dikonsulkan dari Bagian Paru RS Dr. M. Djamil Padang pada tanggal 12/11/2010. Pasien dikonsulkan dengan diagnosis benda asing lampu LED di bronkus yang gagal diekstraksi dan sekalian alih rawat ke bagian THT. Sebelumnya pasien masuk IGD pada tanggal11/11/2010 dan telah dilakukan dua kali tindakan bronkoskopi. Bronkoskopi pertama di Ok IGD tanggal 11/11/2010 dan bronkoskopi kedua dilakukan di OK sentral tanggal 12/11/2010. Keduanya menggunakan bronkoskop fleksibel, tapi tidak berhasil mengeluarkan benda asing. Kemudian pasien ini dikonsulkan dan sekalian alih rawat dari bagian Paru ke bagian THT.

Dari anamnesis didapatkan satu minggu sebelumnya pasien bermain sambil menggigit lampu LED yang merupakan bola lampu dari korek api yang telah rusak, kemudian pasien bermain sambil berlari, tiba-tiba bola lampu LED tersebut tersedak. Pasien terbatuk-batuk kuat kemudian batuk tersebut menghilang. Tidak ada riwayat membiru. Ibu pasien menunggu bola lampu tersebut keluar di buang air besar pasien, tapi ternyata tidak keluar. Setelah tiga hari timbul batuk berdahak. Tidak sesak. Tidak terdapat demam. Orang tua pasien baru membawa ke IGD RS Dr. M Djamil Padang pada hari ketujuh setelah tersedak.

Dari pemeriksaan fisik didapatkan keadaan umum sedang, kesadaran komposmentis, tekanan darah 120/70 mmHg, nadi 99x/menit, nafas $24 \mathrm{x} /$ menit, temperatur $36,5^{\circ} \mathrm{C}$, dan berat badan16 $\mathrm{kg}$. Pada dinding dada tidak ditemukan retraksi. Pada auskultasi suara ditemukan suara nafas berkurang pada paru kanan, tidak ditemukan stridor dan wheezing. Pada status lokalis THT pemeriksaan telinga, hidungdan tenggorok dalam batas normal. Laringoskopi indirek sukar dilakukan karena anak tidak kooperatif. Pada pemeriksaan laboratorium

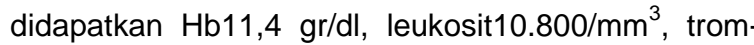
bosit327.000/mm ${ }^{3}$, PT15,6 detik dan APTT51,4 detik.

Dari pemeriksaan penunjang rontgen foto toraks posisi Antero Posterior (AP) dan lateral, terlihat benda asing setinggi vertebra torakal VI-VII (gambar 1), dan setelah gagal dilakukan ekstraksi, terlihat benda asing tidak berpindah posisi (gambar 2).

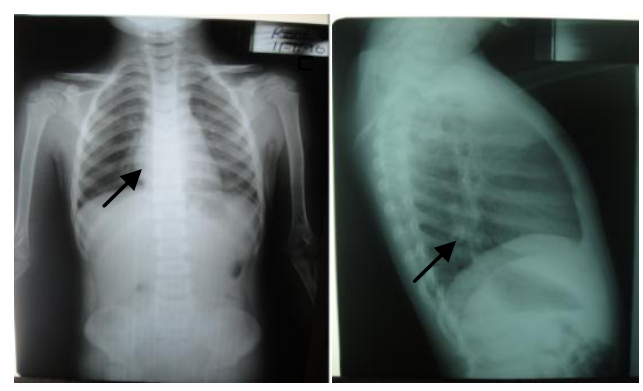

Gambar 1. Foto toraks AP dan lateral sebelum dilakukan ekstraksi, tampak benda asing setinggi Th VI-VII. 

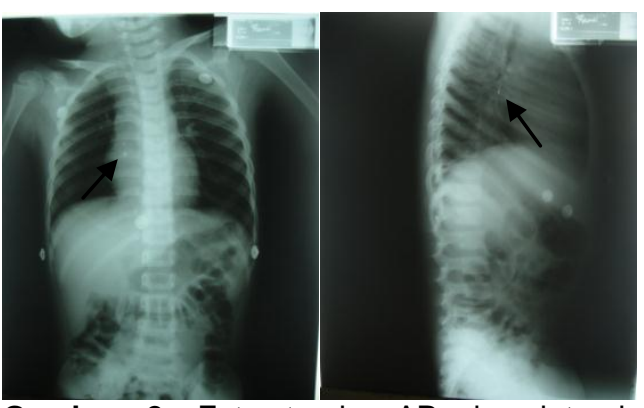

Gambar 2. Foto toraks AP dan lateral setelah dilakukan ekstraksi, tampak benda asing tidak berpindah posisi.

Pada pasien ini karena telah dilakukan 2 kali tindakan bronkoskopi dan dari keterangan Bagian Paru, telah terdapat udem pada trakea, maka diputuskan untuk dilakukan tindakan konservatif dulu selama 4 hari untuk menghilangkan udem dan direncanakan tindakan bronkoskopi pada tanggal 16/10/2010. Bila ada kegawatan obstruksi jalan nafas, akan dilakukan bronkoskopi emergensi. Pada pasien ini diberikan terapi injeksi ceftriaxon2x $800 \mathrm{mg} / \mathrm{iv}$, injeksi dexametason pertama diberikan bolus $8 \mathrm{mg} / \mathrm{iv}$, dilanjutkan dengan 3 × 2,5 mg/ivdan ambroxol sirup 3 $x 15 \mathrm{mg}$.

Follow up hari pertama rawatan.

Dari anamnesis didapatkan tidak ada demam, tidak ada sesak nafas, ada batuk berdahak. Keadaan umum sedang, kesadaran komposmentis, tekanan darah 110/70 mmHg, nadi 99x/menit, nafas 22x/menit. Pada pemeriksaan THT didapatkan pada pemeriksaan telinga, hidung, tenggorok tidak ada kelainan. Pada pemeriksaan paru, stridor tidak ada, wheezing tidak ada, suara nafas berkurang pada lapangan paru kanan. Pasien didiagnosis dengan benda asing lampu LED di bronkus kanan. Diberikan terapi injeksi ceftriaxon 2x800 mg/iv, injeksi dexametason $3 \times 2,5 \mathrm{mg} / \mathrm{iv}$, ambroxol sirup $3 \times 15 \mathrm{mg}$.

Follow up hari kedua rawatan.

Dari anamnesis didapatkan tidak ada demam, tidak ada sesak nafas, ada batuk berdahak. Keadaan umum sedang, kesadaran komposmentis, tekanan darah, nadi $90 \mathrm{x} /$ menit, nafas $24 \mathrm{x} /$ menit. Pada pemeriksaan THT, telinga, hidung, tenggorok dalam batas normal. Pada pemeriksaan paru, stridor tidak ada, wheezing tidak ada, suara nafas menurun pada paru kanan. Diagnosis benda asing suspect lampu
LED di bronkus kanan. Pasin diberikan terapi terapi injeksi ceftriaxon 2x800 mg/iv, injeksi dexametason $3 \times 2,5 \mathrm{mg} / \mathrm{ivdan}$ ambroxol sirup $3 \times 15 \mathrm{mg}$, kemudian pasien diminta toleransi operasi dari bagian anak dan anestesi untuk dilakukan tindakan bronkoskopi dalam narkose umum.

Pada tanggal 16/11/2011 dilakukan tindakan bronkoskopi terapeutik, sebelum dilakukan tindakan bronkoskopi dilakukan rontgenfoto toraks AP dan lateral, didapatkan hasil posisi benda asing tidak berubah (gambar 3).

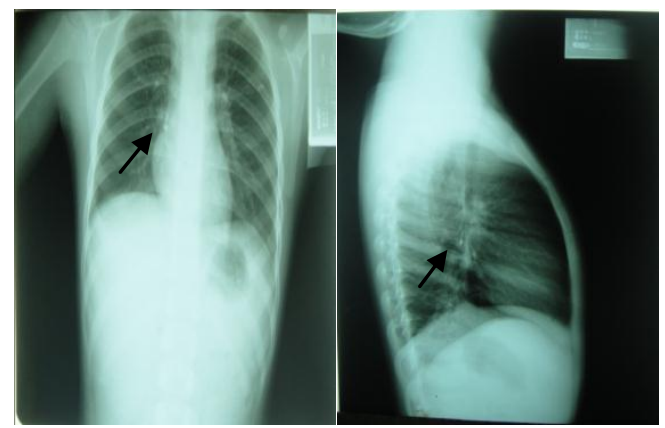

Gambar 3. Foto toraks AP dan lateral sebelum masuk kamar operasi, dimana benda asing tidak berpindah posisi.

Laporan operasi, pasien tidur di meja operasi posisi supine dalam narkose umum, kepala berada digaris tengah dan dipegang asisten dengan posisi hiperekstensi. Laringoskop lurus (macintosh) dipegang dengan tangan kiri dimasukkan ke rongga mulut dari sisi kanan (tangan kanan atau jari tengah dan jempol membuka rongga mulut), setelah tampak epiglotis, laringoskop dimasukkan sedikit dibawah epiglotis dan bersamaan dasar lidah diangkat sehingga rima glotis tampak. Bronkoskop rigid ukuran $5 \mathrm{~mm} \times 30 \mathrm{~cm}$ dipegang dengan tangan kanan masuk dari sisi tengah, pandangan dipindahkan pada bronkoskop dan ujung distal bronkoskop harus berada di pita suara. Bronkoskop dimasukkan ke rima glotis dengan memutar ke kanan $90^{\circ}$, setelah masuk ke trakea, bronkoskop kembali diputar ke kiri $90^{\circ}$ dan laringoskop dilepas, kemudian tangan kiri yang memegang bronkoskop. Bronkoskop dimasukkan menelusuri trakea, sekret dihisap, tidak tampak benda asing di trakea, bronkoskop diteruskan ke karina, dan diteruskan ke bronkus kanan dengan memiringkan kepala ke kiri, tampak benda asing yang ditutupi sekret, sekret dihisap, posisi benda asing bagian 
tajam berada diatas, benda asing dijepit dengan maksum dan ditarik keluar melewati bronkoskopdan berhasil dikeluarkan. Benda asing berukuran 1,3 x 0,3 cm. (gambar 4). Kemudian dilakukan evaluasi, tampak dinding bronkus sedikit hiperemis, tidak tampak ekskoreasi, tidak ada perdarahandantidak ada udem.

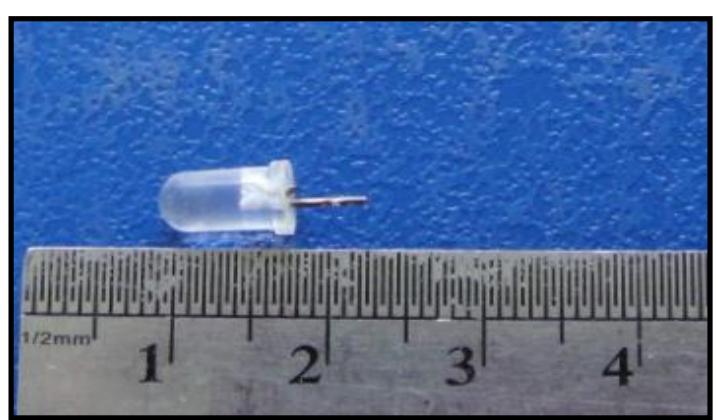

Gambar 4. Benda asing lampu LED

Setelah ekstraksi benda asing tidak terdapat sesak, tidak ada emfisema subkutis dan tidak ada darah keluar dari mulut. Terapi diberikan infus Kaen 1B 4 tetesan makro per menit, injeksi ceftriakson 2 x800 mg/iv, injeksi dexamethason 3x2,5mg/iv dan parasetamol sirup $3 \times 160 \mathrm{mg}$.

Follow up hari pertama pasca operasi.

Dari anamnesis didapatkan tidak terdapat demam, tidak ada sesak, tidak terdapat batuk. Pada pasien ini dilakukan rontgen foto toraks ulang, dengan kesan, tidak didapatkan kelainan pada paru (gambar 5). Pasien ini diberikan terapi injeksi seftriakson 2x800 mg/iv, injeksi deksametason 3x2,5 $\mathrm{mg} / \mathrm{iv}$ dan parasetamol sirup $3 \times 160 \mathrm{mg}$.

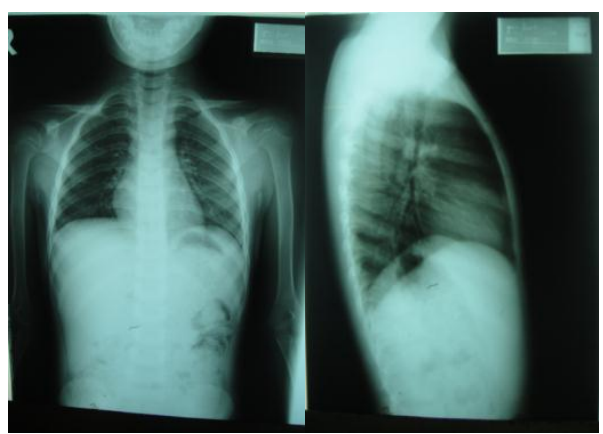

Gambar 5. Foto toraks ulang, tidak didapatkan kelainan

Pasien dipulangkan 2 hari pasca bronkoskopi, dengan terapi cefixim sirup $2 \times 50 \mathrm{mg}$, para- cetamol $3 \times 160 \mathrm{mg}$ bila perlu. Pada hari ke-9 post ekstraksi benda asing pasien kontrol ke poli THT. Dari anamnesa tidak terdapat keluhan. Pada pemeriksaan fisik tidak ditemukan wheezing, tidak ditemukan stridor, tidak demam. Pasien dianjurkan kontrol ke poli THT bila ada keluhan.

\section{DISKUSI}

Telah dilaporkan suatu kasus aspirasi benda asing lampu LED di bronkus kanan pada seorang anak perempuan berusia 5 tahun. Lampu LED (lightemitting diode) adalah suatu semikonduktor yang memancarkan cahaya monokromatik yang tidak koheren ketika diberi tegangan. ${ }^{2}$

Latifi dkk ${ }^{11}$ pada penelitiannya tahun 19942003 di Kosovo mendapatkan kejadian aspirasi benda asing pada laki-laki sebesar 59\% dan perempuan $41 \%$, angka kejadian pada umur 0-3 tahun sebanyak $68 \%$, pada umur 4-7 tahun sebanyak $20 \%$. Cataneo ${ }^{8}$ mendapatkan angka kejadian pada laki-laki sebesar $57 \%$, pada perempuan sebesar $43 \%$, dimana $8 \%$ ditemukan pada usia dibawah 16 tahun.

Benda asing teraspirasi lebih sering pada anak-anak karena mempunyai kebiasaan meletakkan atau menggigit benda di mulut sambil bermain/berlari dan pada saat tertentu anak kurang diawasi orang tua. $^{1,6-8}$

Jenis benda asing yang teraspirasi bervariasi dari masing-masing negara tergantung budaya, sosial dan ekonomi dan ketersediaan jenis benda asing yang berpotensi mengancam jiwa. Sebagian besar dari benda asing yang teraspirasi adalah benda organik yaitu kacang sebesar 62\%, sedangkan benda yang terbuat dari sebesar $1,2 \%{ }^{11,12}$ Pada pasien ini benda asingnya adalah benda inorganik yang terbuat dari logam dan kaca, tapi belum ditemukan adanya laporan kasus aspirasi lampu LED ini.

Dari anamnesis seseorang yang mengalami aspirasi benda asing di saluran nafas akan mengalami tiga stadium. Stadium pertama merupakan gejala permulaan yaitu riwayat tersedak, batukbatuk hebat secara tiba-tiba (violent paroxysmalof coughing), rasa tercekik (choking), rasa tersumbat di tenggorok (gagging), sesak nafas yang tiba-tiba, wheezing yang tiba-tiba, rasa tercekik atau obstruksi jalan nafas akut. Stadium dua yaitu interval asimpto- 
matis, pada stadium inigejalanya menghilang. Staduim ketiga yaitu telah terjadi gejala komplikasi infeksi sebagai akibat reaksi jaringan terhadap benda asing, hingga timbul batuk-batuk, stridor dan berkurangnya suara nafas pada auskultasi, hemoptisis, pneumonia, dan abses paru. ${ }^{5,13}$ Ada banyak kasus dengan gejala asma akut, yang diterapi tapi tidak ada perbaikan. ${ }^{3,11}$

Benda asing yang teraspirasi tanpa menimbulkan obstruksi akut, akan menimbulkan reaksi tergantung dari jenisnya, organik atau anorganik. Aspirasi benda asing yang anorganik, jika tidak menimbulkan obstruksi, dapat asimptomatis pada waktu yang lama. Gejala yang sering adalah batuk $68,3 \%{ }^{7}{ }^{7}$ Cataneo ${ }^{8}$ mendapatkan gejala batuk sebesar $68 \%$, rasa tercekik $54,9 \%$ dan sesak $28,7 \%$.

Pada pasien ini dari anamnesis terdapatnya riwayat tersedak benda asing dan batuk yang paroksismal, tapi gejala hilang beberapa saat setelah aspirasi benda asing, batuk timbul lagi pada hari ke-3, tapi sudah batuk berdahak.

Pada pemeriksaan fisik ditemukan adanya suara nafas yang berkurang pada paru kanan. Terdapatnya gejala akibat aspirasi benda asing bervariasi tergantung pada lokasi, jenis, ukuran, bentuk, sifat iritasinya terhadap mukosa, lama benda asing di jalan nafas, derajat sumbatan serta adanya komplikasi dari benda asing. ${ }^{9,12}$ Hasdraz $^{13}$ mendapatkan pada pemeriksaan fisik suara nafas yang menurun pada $88,9 \%$ kasus, wheezing pada $51,9 \%$ kasus dan sianosis pada 6,2 kasus. Pada pasien ini ditemukan adanya suara nafas yang berkurang pada paru kanan, tidak sesak dan tidak ada tanda infeksi, hal ini karena benda asing yang terbuat dari logam dan kaca kurang iritatif dan ukurannya tidak menyumbat total bronkus kanan.

Pada pasien ini dilakukan rontgen foto toraks AP dan lateral dan tampak gambaran radioopak setinggi vertebra torakal VI-VII. Menurut Ripley ${ }^{16}$ rontgen foto toraks harus dilakukan pada kasus aspirasi benda asing ataupun yang diduga aspirasi benda asing, meskipun lebih dari 90\% dari benda asing adalah radiolusen. Menurut Kalyanappagol adanya gambaran pneumonia pada13,1\%kasus, atelektasis pada $12 \%$ kasus dan terlihat benda asing pada $2,7 \%$ kasus, sedangkan gambaran normal didapatkan pada $63,7 \%$ kasus. $^{14}$
Pada pasien ini dari foto toraks PA dan lateral tampak gambaran benda asing yaitu gambaran radioopak setinggi vertebra torakal VI-VII.

Setelah teraspirasi, benda asing dapat tersangkut pada 3 tempat yaitu di laring, trakea dan bronkus di mana sekitar $80-90 \%$ tersangkut di bronkus. Pada pasien ini benda asing tersangkut di bronkus utama kanan karena ukurannya lebih lebar dan hampir merupakan garis lurus dengan trakea, sedangkan bronkus kiri membuat sudut dengan trakea. ${ }^{9,16 .}$ Anatomi trakea dan bronkus (gambar 6). ${ }^{17}$

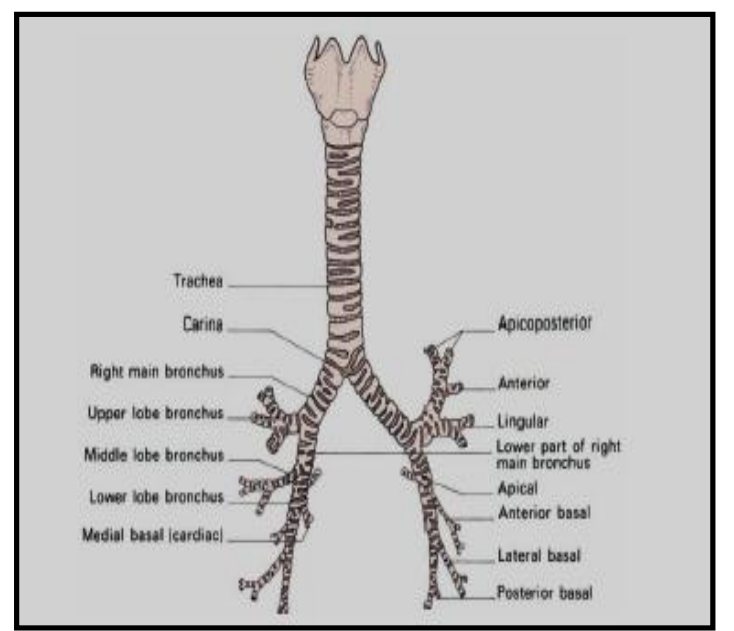

Gambar 6. Trakea dan bronkus ${ }^{17}$

Video fluoroskopi merupakan cara terbaik untuk melihat saluran nafas secara keseluruhan, dapat mengevaluasi pada saat ekspirasi dan inspirasi dan adanya obstruksi parsial. $^{9}$ Pemeriksaan laboratorium darah diperlukan untuk mengetahui adanya gangguan keseimbangan asam basa sertaa danya tanda infeksi trake obronkial. ${ }^{10}$ Pada pasien ini tidak dilakukan pemeriksaan astrup karena pasien tidak sesak, tapi didapatkan tanda leukositosis.

Benda asing di saluran nafas harus segera dikeluarkan dalam kondisi optimal dengan trauma yang minimal untuk mencegah komplikasi. Pada pasien ini dilakukan tindakan bronkoskopi di ruangan bedah sentral, dan optimalisasi alat. ${ }^{13}$ Ada beberapa faktoryang menentukan keberhasilan penatalaksanaan benda asing di saluran nafas, yaitu: 1.Tim yang berpengalaman dalam ekstraksi benda asing di saluran nafas, 2.Kerjasama yang baik antara operator dengan tim anestesi, 3.Ketersediaan alat yang sesuai dengan kebutuhan. ${ }^{16}$ 
Bronkoskop kaku merupakan pilihan untuk ekstraksi benda asing di saluran nafas, disamping juga digunakan untuk diagnosis pada kasus kecurigaan benda asing. ${ }^{8}$ Pada pasien ini dipilih bronkoskop kaku dengan pertimbangann pernafasan lebih terkontrol, oksigenasi adekuat, lumen lebih besar, sehingga memudahkan melakukan tindakan, dan untuk mengatasi bila terdapat perdarahan. Kekurangan bronkoskop fleksibel adalah pernafasan kurang terkontrol, dan lumen alat terlalu kecil untuk bisa memasukkan benda asing. ${ }^{7,9}$ Pilihan memakai bronkoskop kaku atau flexibel tergantung pada pilihan operator, lokasi benda asing dan usia pasien. ${ }^{8}$ Ukuran benda asing harus diketahui dengan membuat duplikat dan mencobanya dengan cunam yang sesuai, sesaat sebelum melakukan bronkoskop dibuat foto toraks untuk menilai kembali letak benda asing. Komunikasi antara operator dan dokter ahli anestesi penting untuk menentukan rencana tindakan. ${ }^{11,12}$ Penyulit pada penatalaksanaan benda asing di bronkus antara lain faktor penderita, lamanya benda asing teraspirasi, lokasi benda asing, kelengkapan alat, kemampuan tenaga medis dan anestesi yang terampil. ${ }^{10}$

Komplikasi benda asing teraspirasi dilaporkan $22-33 \%$ diantaranya pneumomediastinum, pneumotoraks, hidropneumotoraks, stenosis bronkial, abses, ateletaksis, pneumonia, bronkiektasi dan bronkospasme, dimana pneumonia merupakan komplikasi yang paling sering terjadi. ${ }^{2,7,12}$ Pada pasien ini ekstraksi benda asing dilakukan tanpa menimbulkan komplikasi.

\section{KESIMPULAN}

1. Pada kasus inidari anamnesis didapatkan riwayat tersedak benda asing lampu LED. Batuk yang paroksismal diikuti fase asimptomatik dan hari ketiga timbul batuk berdahak. Pada pemeriksaan torak ditemukan suara nafas yang berkurang di paru kanan. Hasil pemeriksaan laboratorium didapatkan leukositosis dan dari foto toraks tampak benda asing radioopak.

2. Keberhasilan bronkoskop kaku pada pasien ini karena oksigenasi lebih terjamin, dan ukuran skop yang memungkinkan benda asing bisa dilindungi masuk ke dalam skop waktu melakukan ekstraksi.
3. Kegagalan ekstraksi menggunakan bronkos kopfleksibel pada kasus ini dimungkinkan karena sulitnya oksigen sewaktu tindakan, sehingga alat bronkoskopi harus keluar masuk bronkus untuk bergantian dengan oksigen anestesi.

4. Saran untuk meminimalisir kasus aspirasi benda asing pada anak-anak perlunya menghindarkan benda-benda yang bisa teraspirasi dari anak, mengingatkan anak untuk jangan meletakkan benda-benda kecil di mulut dan menjauhkan mainan yang berukuran kecil yang bisa menyebabkan aspirasi pada anak.

\section{DAFTAR PUSTAKA}

1. Brkic F, Umihanic S. Tracheobronchial foreign bodies in children experience at ORL clinic Tuzla, 1954-2004. International Journal of Pediatric Otorhinolarygology 2007; 71: 909-15.

2. Dioda cahaya. Available from http: www//id.wikipedia.org/wiki/Dioda-cahaya.

3. Asif M, Shah SA, Khan F, Ghani R. Foreign body inhalation-site of impaction and efficacy of rigid bronchoscopy. J Ayub Med Coll abbottabad 2007; 19: 46-8.

4. Asif M, Shah SA, Khan F, Ghani R. Analysis of tracheobronchial foreign bodies with respect to sex, type, and presentation. J Ayub Med Coll Abbottabad 2007; 19: 13-5.

5. Sersar SI, Hamza UA, Abdelhameed WA, Abulmaaty RA, Gowaeli NN, Moussa SA et al. Inhaled foreign bodies : management according to early or late presentation. European Journal of Cardio-thoracic surgery 2005; 28: 369-74.

6. Rina $M$, Quintos TR. Pediatric rigid bronchoscopy for foreign body removal. Philippine journal of Otolaryngology Head and Neck Surgery 2009; 24: 39-41.

7. Doody DP. Foreign body aspiration. In Grillo HC editors. Surgery of the trachea and bronchi. London: BC Decker Inc, 2004. P.707-17.

8. Cataneo AJM, Cataneo DC, Ruiz RL Management of tracheobronchial foreign body in children. Pediatric Surgery Int 2008; 24: 151-6.

9. Jackson C. Bronchoesophagology. In: Bronchoesophagology. Philadelphia and London; 1958. P. 5-34. 
10. Junizaf $\mathrm{MH}$. Benda Asing di Saluran Napas. Dalam : Soepardi EA, Iskandar N, editors. Buku Ajar IImu Kesehatan THT-Kepala LeherJakarta : Balai Penerbit FKUI ;2007.p 259-65.

11. Latifi X, Mustafa A, Hysena Q. Rigid tracheobronchial in the management of airway foreign bodies: 10 years experience in Kosovo. International Journal of Pediatric otolarygology 2006; 70: 2055-9.

12. David E. Eibling, Management of intractable aspiration. In: Byron J.Bailey\&Jonas T.Johnson editors, Head \& Neck Surgery otolaryngology; 1998 ed. $4^{\text {th }} . p 733-43$.

13. Hasdiraz I, Oguzkaya F, Bilgin M, Bicer C. Complication of bronchoscopy for foreign body removal: experience in 1035 cases. Ann saudi Med 2006; 26: 283-7.

14. Kalyanappagol VT, kulkarni NH, Bidri LH. Management of tracheobronchial foreign body aspiration in pediatric age group- 10 year retrospective analysis 2007; 51: 20-3.

15. Perkasa MF. Ekstraksi benda asing di laring dengan neuroleptic anesthesia. Case report original artikel 2009: 22; 20-3.

16. Ripley DP, Henderson AK. A case of aspiration: the importance of early diagnosis and clinical suspicion. Primary care Respiratory Journal 2007; 16: 191-3.

17. Ellis $\mathrm{H}$. Clinical anatomy. Blackwell publishing 2006; ed: $11^{\text {th }}: p 19-21$. 